\title{
三角形パッチによろ輪郭線からの側面生成法の改良 *
}

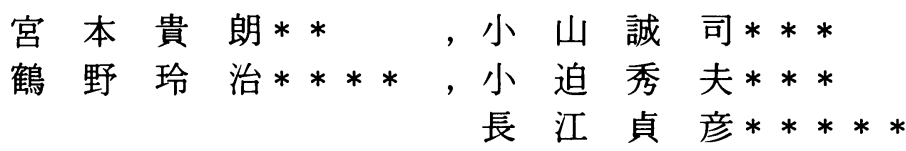

\section{1. はじめに}

3 次元的な広がりをもつ物体（人体，組織，脈管な ど）の解析には，断面の 2 次元像だけではなく， 3 次 元的な情報が必要とされる。これは 3 次元像のもつ情 報量が多いことと，直感的な認識性を向上させるため である。しかし，医学分野では CT 像，MRI 像，超 音波断層像など 2 次元断面図でしか情報を得ることが できず，これら連続する断面図から 3 次元像を再構築 する研究が盛んに行われている。

2 次元断面図から得られる輪郭線データを基にして その側面を生成するには，大別すると，スプライン等 の種々の補間手法を用いて曲面を生成する方法 ${ }^{1)}$ と, 曲面を比較的小さな平面の集合で近似する方法とがあ る。前者は, より自然な側面が生成される反面, 膨大 なデータと処理が必要となる。一方，後者は，曲面を 平面で近似する不自然さは残るものの，その手軽さか ら広く一般的に用いられている。また多くの場合, 側 面生成後に phong shading ${ }^{2)}$ 等を施せば, この不自 然さもある程度解消することができる。

ここでは, 3 次元像再構築の種々の手法のうち, 3 次元側面を三角形パッチにより生成する手法について 検討を行った。この手法の特徵は, 輪郭線データのみ から 3 次元側面を生成できるため, モアレトポグラフ 1一や地図の等高線からの 3 次元像再構築に対して も，適用可能なことである。また，計算負荷が比較的 軽いため, パーソナルコンピュータでも処理できる。

しかし，これまでの報告例3)-5)では, 複雑な輪 郭形状に対して, 不自然な側面を生成する場合が多く, 対話的に処理する必要があった。

本研究は, 上記の問題を解決するため, 3 次元側面
を三角形パッチにより生成する手法について, 複雑な 輪郭形状に対しても自動的に, より自然な形状の 3 次 元側面を生成できるよう改良したものである。

一般的に，三角形パッチ生成問題について考える場 合, 輪郭線は連続線分で近似した多角形データとして 取り扱う。自然な三角形パッチの生成を考える際に,

輪郭曲線をどのような連続線分で近似するかは重要な 要素となるが,ここでは, 画像処理後のディジタル輪 郭線を全て等間隔でサンプルした多角形データを対象 とする。

\section{2. グラフ理論との対応}

$2 つ の$ 輪郭線（以下，隣接輪郭線と呼ぶ）の側面を 三角形パッチで生成する場合を考える。例えば，図 1 のように，隣接輪郭線が $m$ 個の頂点 $P_{0}, P_{1}, \cdots \cdots$, $P_{m-1}$ と $n$ 個の頂点 $Q_{0}, Q_{1}, \cdots \cdots, Q_{n-1}$ で構成されて いるとする。このとき, 生成される三角形パッチは, 片側の輪郭線の一部に含まれる辺 (contour segment)

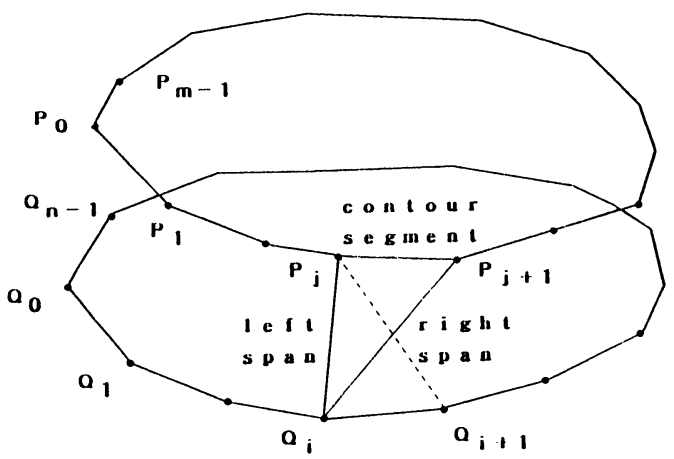

図 1 輪郭線デー夕

* 平成 3 年 5 月 28 日受付

**大阪府立大学計算センター

$* * *$ 大阪府立大学工学部

**** 近畿大学理工学部

$* * * * *$ 近畿大学文芸学部 
と, その両側の頂点から他の輪郭線側の頂点へ引いた 2 辺（span）で構成され, 上側の陯郭線上に contour segment を持つ三角形群 $P_{j} Q_{i} P_{j+1}$ と下側の輪郭線上 に contour segment を持つ三角形群 $Q_{i} P_{j} Q_{i+1}$ に分類 される。三角形群 $P_{j} Q_{i} P_{j+1}$, 三角形群 $Q_{i} P_{j} Q_{i+1}$ の それぞれに対して, 線分 $P_{j} Q_{i}$, 線分 $Q_{i} P_{j}$ を left span, 線分 $Q_{i} P_{j+1}$, 線分 $P_{j} Q_{i+1}$ を right span とし て区別する。生成される三角形パッチの集合が，隣接 輪郭線間の曲面を完全に構成するには, 以下の条件を 満たす必要がある。

(1) contour segment に対し唯一つの三角形が対応 する。したがって，三角形は $m+n$ 枚である。

(2)输郭線間の span がある三角形の left span とな るときは, 必ず別の三角形の right span にも なっている。

以後, この条件を満足している三角形パッチからな る面を acceptable surface と呼ぶ。

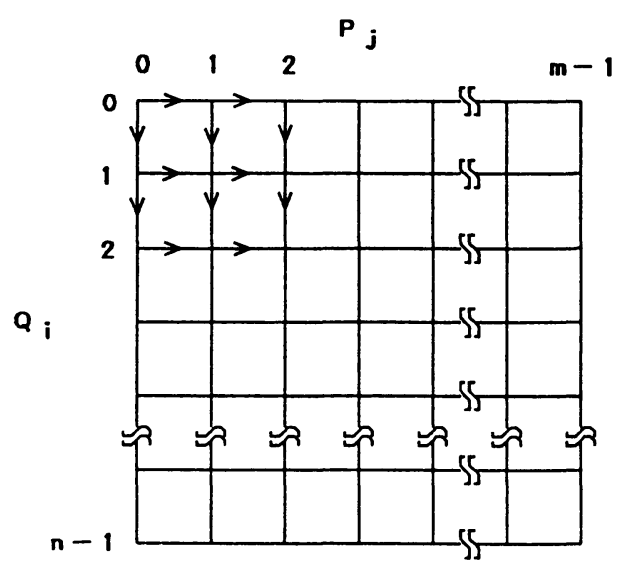

図 2 グラフとの対応

さて, 図 1 における全ての acceptable surface は, 図 2 のような有向グラフ $G[V, A]$ の経路として表さ れる。ここでは, 経路, 接点, 枝はすべて無定義用語 として用い, 接点 $V は$ 隣接輪郭線の全ての span に対 応し, 枝 $A$ は 2 つの span の間に生成される三角形に 対応する。すなわち,

$$
V=\left\{V_{i j} \mid i=0,1, \cdots \cdots n-1 ; j=0,1, \cdots \cdots m-1\right\}
$$

であり， $V_{i j}$ は線分 $P_{j} Q_{i}$ に対応する。

また，

$$
A=\left\{\left[V_{l k}, V_{t s}\right] \mid s=k \text { のとき } t=l+1,\right.
$$

$$
\text { または } s=k+1 \text { のとき } t=l\}
$$

であり, $\left[V_{l k}, V_{t s}\right]$ は線分 $P_{k} Q_{l}$ を left spanに持ち線 分 $P_{s} Q_{t}$ を right span に持つ三角形に対応する。した がって, 隣接㖮郭線間の acceptable surface はグラフ の左上の接点 $V_{00}$ から右下の接点 $V_{n-1 m-1}$ までの経 路に対応する。

$m, n$ 点からなる隣接輪郭線間の acceptable surface の数を関数 $A[m, n]$ とすると,

$$
A[m, n]=\frac{[(m-1)+(n-1)] !}{(m-1) !(n-1) !}
$$

となり, $m, n$ が増加すると膨大な数になる。

一方，最適解を選ぶ基準として，三角形パッチ $A$ に数值を対応付ける関数を $\phi: A \rightarrow R$ とし, 全ての枝 $a$ に $\phi_{a}$ を重みとして与える。 acceptable surface が $m+n$ の枝 $a_{1}, a_{2}, \cdots \cdots a_{m+n}$ を通るとき，その経路の 評価関数 $\Phi$ は,

$$
\Phi=\sum_{\mathbf{k}=1}^{\mathrm{m}+\mathrm{n}} \phi \mathrm{a}_{\mathbf{k}}
$$

となる。したがって，あらかじめ定義された条件を満 たすように経路を決定し， $\Phi$ の值で評価する。

\section{3. 三角形パッチの生成アルゴリズム}

\section{1 全経路探索による最適解}

ここでは，最適な acceptable surface を得るための 評価関数として Fuchs ${ }^{3)}$ の方法を採用した。この方 法は, 隣接輪郭線間の最適な面とは, acceptable surface の中でその表面積が最小であるものと定義して いる。したがって，各枝の重み $\phi$ をその枝が示す三角 形の面積とし, それらの和 求めれば, 表面積最小の acceptable surface が求めら れる。

ところが, 全経路探索を用いて最適解を求めるには, $m \times n$ 通りの acceptable surface の組み合わせについ て計算する必要があり, 莫大な処理時間を要する。そ こで， heuristic な方法を用いて， $m+n$ 通りの組み 合わせについて計算することにより最適解の近似解を 求める方法が幾つか提案されている。

\subsection{Heuristic method}

輪郭線データのある特徵量についての情報から， $m+n$ 通りの組み合わせを計算することで高速に近似 解を得る方法であり, 最適性よりも高速性が要求され る場合によく用いられる。基本的には, グラフの枝に 
与えられる重みが(1)局所的な条件のみから決定され る，(2)処理時間が短い，という条件を満たすように， 節点 $V_{00}$ から $V_{n-1 m-1}$ までの経路を求める。具体的 には, 以下のような手順で解を求める。

まず，輪郭線間の距離が最短による頂点を三角形パ

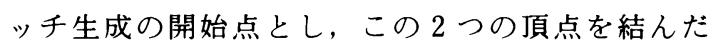
span を考え，これを節点 $V_{00}$ とする。次に，この点 がグラフの左上となる図 3 のようなグラフを考え，

$V_{00}$ から $V_{n-1 m-1}$ までの経路を求める。いま，ある 節点 $V_{i j}$ 上にいるとき，次の結合は $V_{i j+1}$ か， $V_{i+1}$ かの 2 通りだけである。これを最後の $V_{n-1 m-1}$ に到 着するまで繰り返す。以下で heuristic method の代表 的な手法について比較検討を行う。

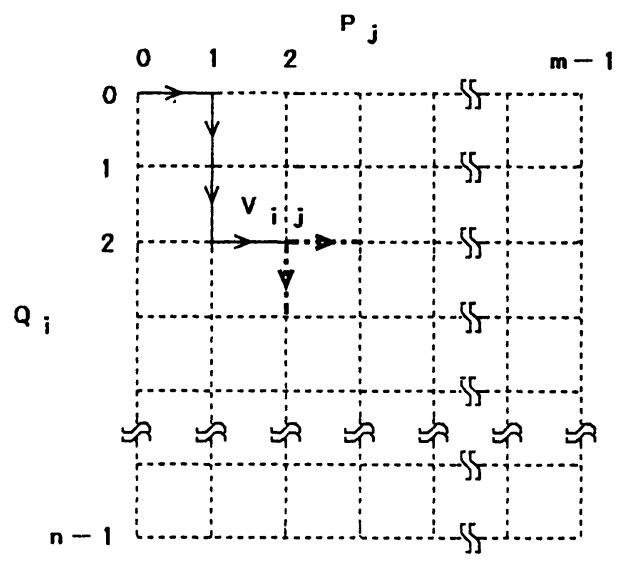

図 3 Heuristic Method

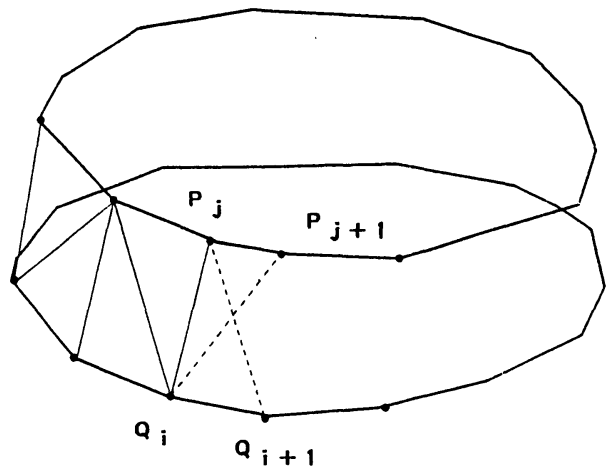

図4 Fuchsの方法の近似

\subsubsection{Fuchsの方法の近似}

Fuchs の表面積最小解を求める方法は, heuristic
に近似解を求める方法に改良できる。枝の重みを次に 生成する三角形の面積とし, 面積の小さい三角形パッ チを生成する。いま，図4 のように， $V_{i j}$ まで処理が 終わっている場合, 次に生成する三角形パッチの候補 である三角形 $P_{j} Q_{i} Q_{i+1}$ と三角形 $P_{j} P_{j+1} Q_{i}$ の面積を 比較し, 面積の小さくなる方の span を選択する。

\subsubsection{Christiansenの方法4)}

Christiansen の方法は，枝の重みを新たに生成す る spanの長さとし, 短い方の span を含む三角形パッ チを生成する。この手法は, 例えば, 図4のように, $V_{i j}$ まで処理が終わっている場合には線分 $P_{j+1} Q_{i}$ と 線分 $P_{j} Q_{i+1}$ の長さを比較し, 短い方を span として 選択する。特徵は, 隣接輪郭線の長さと形状, 輪郭の 重心位置が類似しているとき，最も適切に三角形パッ チを生成する。

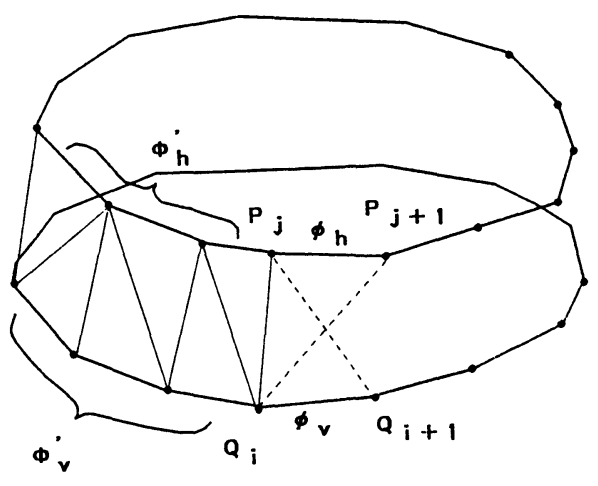

図 5 Ganapathyの方法

\subsubsection{Ganapathy の方法 5)}

Ganapathy の方法は, 隣接輪郭線の長さを各々正 規化し，三角形パッチ生成処理済みの contour segment の長さの差が最小になるように次の三角形パッ チを生成する。まず, 各輪郭線の周囲の長さの和が 1 になるように正規化する。次に，重みは contour segment の長さと定義する。即ち，図 5 のようにある節 点 $V_{i j}$ 上で

$$
\left|\Phi_{h}^{\prime}+\phi_{h}-\Phi_{v}^{\prime}\right|<\left|\Phi_{v}^{\prime}+\phi_{v}-\Phi_{h}^{\prime}\right|
$$

のとき三角形 $P_{j} P_{j+1} Q_{i}$ を生成し，そうでないときは 三角形 $P_{j} Q_{i} Q_{i+1}$ を生成する。グラフの水平枝の重み の和と垂直枝の重みの和の差が小さくなるように経路 を選択する。

この方法は, その時点での三角形パッチの生成が, 

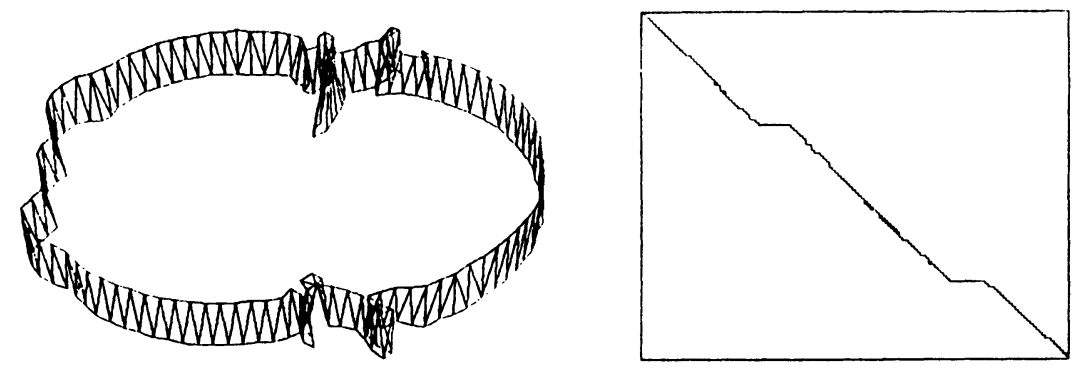

（a）表面绩最小界
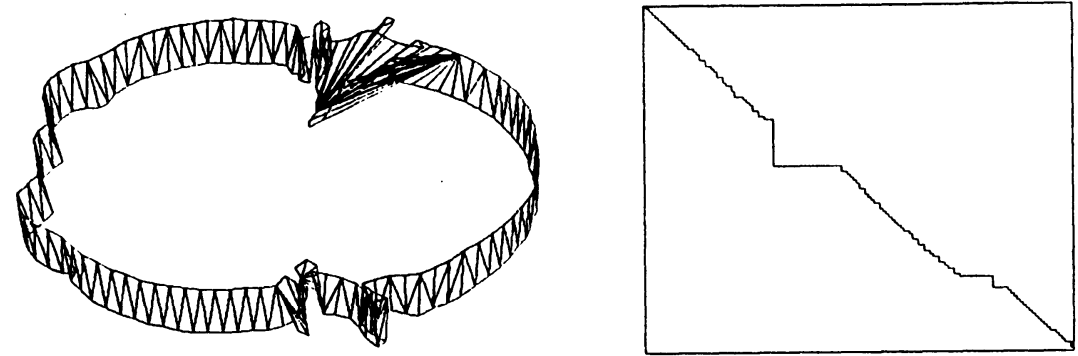

(b) Puchs の法の近以
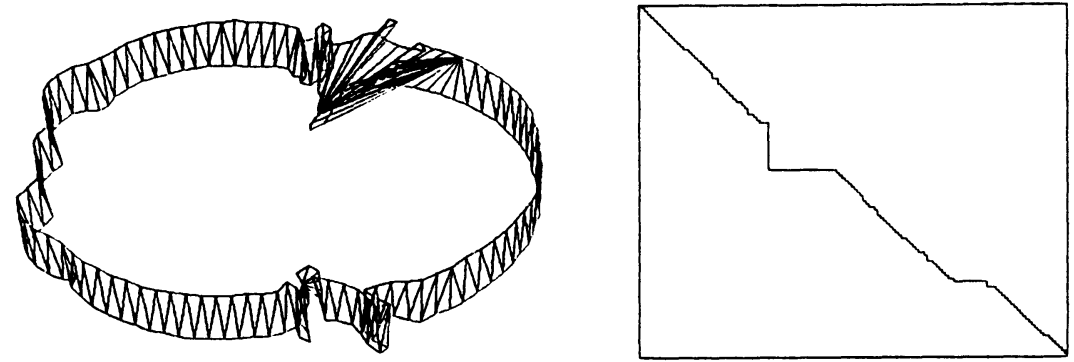

(c) Christiansen 0 方法
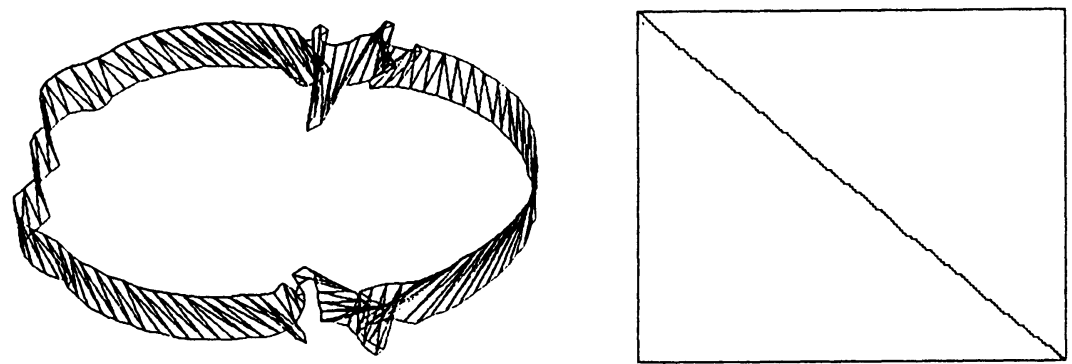

(d) Ganapalthy の方陆

図 6 従来の方法での実行例 
それ以前の結果に影響され，処理の際に多少の記憶領 域が必要となる。しかし，隣接輪郭線の位置関係を問 わないという特長があり，また隣接輪郭多角形が必ず しも平行でなくても, 処理可能という特徵がある。

以下, 本稿ではシミュレーションとして, 実際の CTから得たデータを用いて，上記の各手法について 三角形の生成を行い，比較検討する。

\section{3 シミュレーション}

例として図 6 のような, 大部分が同じ形状で，一部 が大きく異なる隣接輪郭線を用いてシミュレーション を行った。(a)は表面積最小解, (b)は Fuchs の方法の 近似，(c)は Christiansen の方法，(d)は Ganapathy の 方法で，三角形パッチを生成した結果とそのグラフを 表している。生成された三角形パッチの評価基準は， 表面積が小さいほど最適とする Fuchs の考えに従い， 比較のために全経路探索による表面積が最小の最適解 も併せて示す。

表 1 従来の方法の比較

\begin{tabular}{|c|c|c|}
\hline & 表面積 & 䚵算時間 \\
\hline 表面積最小解 & 1.00 & 19.64 \\
\hline Puchs 0)方法0近似 & 1.13 & 0.27 \\
\hline Christiansen 0方法 & 1.13 & 0.05 \\
\hline Canapathy 0)方法 & 1.19 & 0.07 \\
\hline
\end{tabular}

さらに,各方法で生成した三角形パッチの表面積と, 処理時間を表 1 に示す。表面積は表面積最小解を 1 と した時の比で表してある。処理時間は, 三角形パッチ の生成時間のみを測定したものである。使用機器は, NEC PC- 9801 RA 2 (386 モード, 16 MHz) で あり, i 80387 数值演算コ・プロセッサを内蔵してい る。

まず，処理速度を比較すると， heuristic method は， 処理の高速化において非常に効果的である。中でも， Christiansenの方法は，高速に処理していることが分 かる。Ganapathy の方法では，前処理として全長を
求めて逐次割り算する正規化の処理が必要なことか ら，少しオーバーヘッドを生じることが分かる。

次に，側面生成の適当さを比較すると，隣接輪郭線 が類似の形状の部分では, Christiansenの方法がよ り最適な三角形を生成している。しかし，隣接輪郭線 の形状が大きく異なる場合, 表面積の最適性および外 観の見た目でも，Christiansen の方法では，明らか に不自然な三角形パッチを生成する。一方, Ganapathy の方法では隣接輪郭線の形状が類似して いる部分で，少しねじれたような感じの三角形を生成 するが，隣接輪郭線の形状が大きく異なる部分でも比 較的自然な三角形が生成できる。

\section{4. 三角形パッチ生成の改良}

\section{1 概要}

これまでの報告例では上述のように，隣接輪郭線の 形状が大きく異なる部分は, 不都合な側面が生成され, 人間の手によって取り除いたり，あるいは処理を中断 して人間がヒントを与えたりしていた。しかしこれ では heuristic な方法による時間短縮の効果が半減す るだけでなく，側面生成を含んだシステムの自動処理 という点で大きなネックとなる。そこで本研究では, 形状の異なる部分を含む輪郭線データでも, 輪郭形状 の類似性を判定し，2つの heuristic な方法を自動的 に使い分け，自然な三角形パッチを生成する手法を提 案する。この場合, 輪郭線データの形状の類似性を判 定する基準が問題であり，今回は，類似性を判定する 基準についても比較を行った。

\section{2 輪郭線データの類似性の判定}

\subsection{1 頂点間の距離による判定}

隣接輪郭線について, 前処理として Christiansen の方法と同じ手順で各頂点間を接続した際の距離を計 算し, 頂点間距離の平均值を求めておく。三角形パッ チ生成の時, $\operatorname{span}$ の長さが頂点間距離の平均值以下 であれば輪郭形状は類似していると判定し，Christiansen の方法で三角形パッチを生成する。そうでな ければ，輪郭形状は異なっているとし， Ganapathy の方法によって三角形パッチを生成する。

\subsection{2 輪郭線の曲率による判定}

各輪郭線について, 現在処理済みの頂点から次の頂 点へのベクトルを考える。これを方向べクトルと呼ぶ。 隣接輪郭線の 2 つの方向ベクトルの角度を比較し，そ 


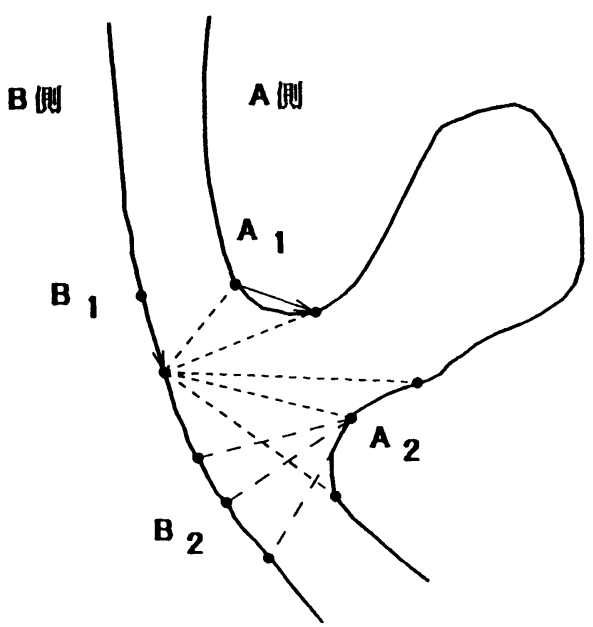

図7陯部線の曲來による分割

の差（曲率）を輪郭線形状の類似性とする。図 7 のよ うに，隣接輪郭線上の曲率が大きく異なると判断した 点を, 各々 $A_{1}, B_{1}$ とする。次に, $A$ 側の点を $A_{1}$ か ら順にサーチし， $B_{1}$ との距離を計算する。通常その 距離は極小値を持ち, その点を検出し $A_{2}$ とする。さ らに, $A_{2}$ との距離が一番近い $B$ 側の点を検出し, $B_{2}$ とする。

このようにして, 4 点 $A_{1}, A_{2}, B_{1}, B_{2}$ を検出し, 区 間 $A_{1}-A_{2}, B_{1}-B_{2}$ の長さの和が各々 1 になるように 正規化し，この区間の三角形の生成は，Ganapathy の方法を用いる。隣接輪郭線の形状が類似している場 合は，輪郭線の曲率を計算しながら，Christiansen の方法で処理する。

\section{3 シミュレーション}

図6と同じ輪郭線データに対して，頂点間の距離に よる判定を用いた例を図 $8(\mathrm{a})$ に，陯郭線の曲率による 判定を用いた例を図 8 (b)に示す。

また，表面積と処理時間の比較の表を表 2 に示す。

表 2 本手法と最適解との比較

\begin{tabular}{|c|c|c|}
\hline & 表面稍 & 勤算時間 \\
\hline 表面積最小解 & 1.00 & 19.64 \\
\hline 頂点間の弫離による判定法 & 1.05 & 0.18 \\
\hline 㭘郭缐の曲事による判定法 & 1.02 & 0.19 \\
\hline
\end{tabular}

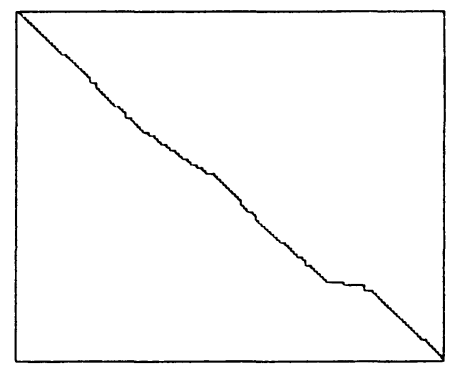

（a）盾点間の医による䑸
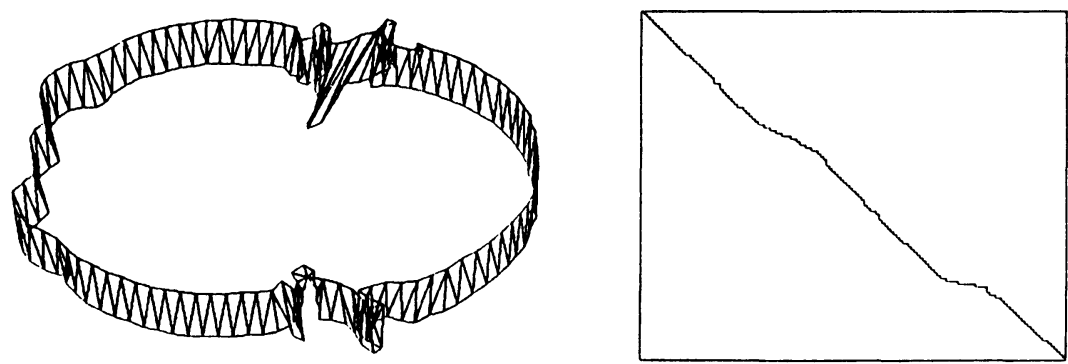

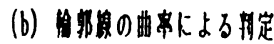

図 8 本手法による実行例 
最後に, 実際の CT から抽出した輪郭線データを用 いた結果を図 $9(\mathrm{a})$ （f)に示す。これは，頭部の一部で あり， 14 層の輪郭線を 5 単位長で重ねたものである。 また，各方法における表面積と処理時間を表 3 に示す。

まず，処理時間を比較すると，改良した手法は前処 理の分だけ，従来の方法よりオーバーヘッドとなる。 しかし，全経探索よりは短い時間で処理しており，十 分その目的は果たしている。

次に, 表面積を比較すると, 従来の方法よりかなり 良好な結果が得られた。実際の CT での比較でもその 効果は顕著であり, 特に複雑な形状であっても，改良 した手法は自然な三角形パッチが生成できた。

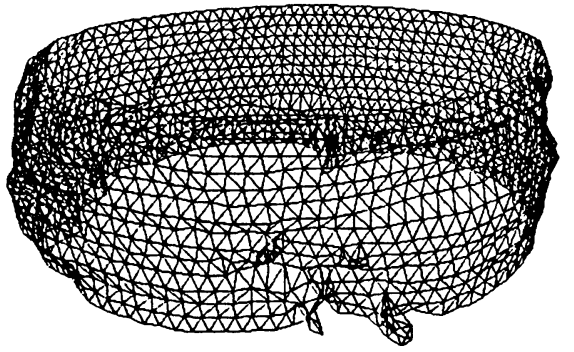

(a) 表面清最小罪

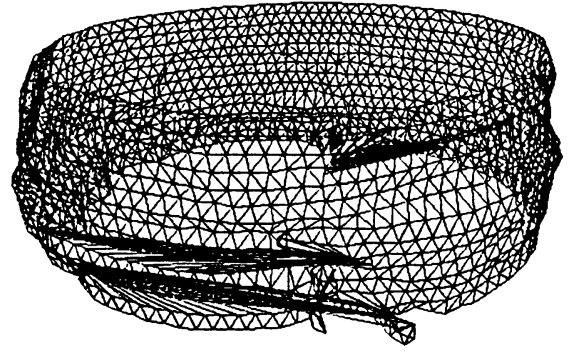

(c) Christiansen 0 方运

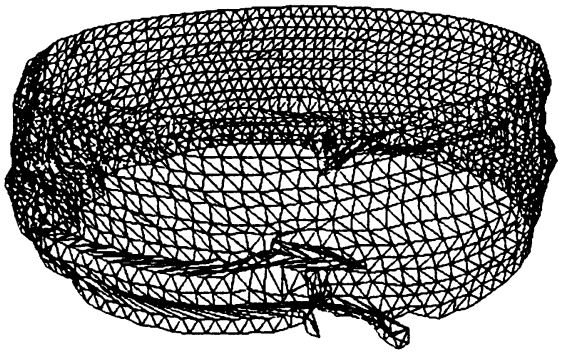

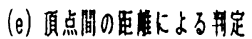

表 3 CTデータでの各手法の比較

\begin{tabular}{|c|c|c|}
\hline & 表面糟 & 䚵算時間 \\
\hline 表面積最小解 & 1.00 & 179.24 \\
\hline Puchsの方法の近似 & 1.43 & 2.89 \\
\hline Christiansen の方法 & 1.22 & 0.51 \\
\hline Ganapathy.の方法 & 1.23 & 1.12 \\
\hline 頂点間の但㓻による判定法 & 1.09 & 2.65 \\
\hline 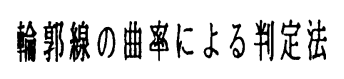 & 1.01 & 1.59 \\
\hline
\end{tabular}

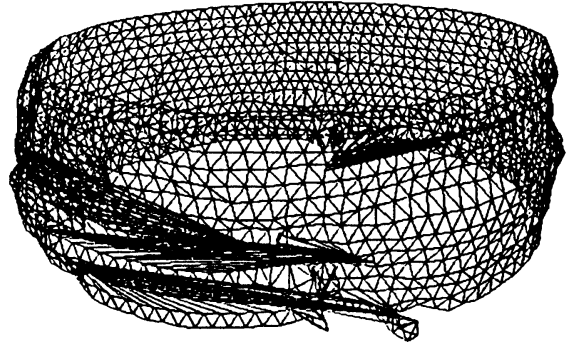

(b) Puchs の方出の近证

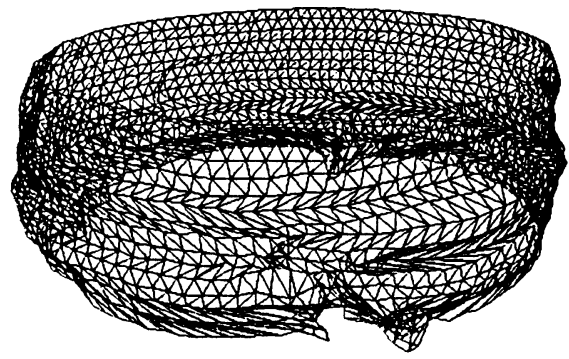

(d) Ganapathy 9方运

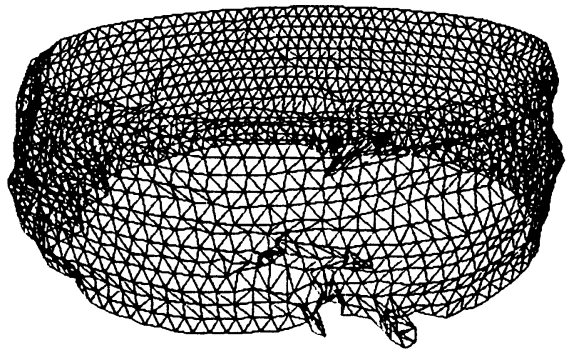

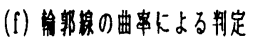

図 9 CTデータでの実行例 


\section{5. おわりに}

輪郭線データから三角形パッチで側面を生成する従 来の方法について, シミュレーションを行い, 考察し た。その結果, 生成される三角形パッチは, 最適解を 表面積最小解とした場合, heuristic methodによる近 似解の精度は陯郭線の形状に大きく依存することが判 明した。そこで，輪郭線データを形状の類似度によっ て分割し，従来の方法をそれぞれに適した部分に用い るように改良した結果, 形状に依存せず，精度のよい 近似解を得ることができた。

今後の課題としては, まず, 陯郭形状の類似性の判 定方法に改良の余地がある。特に，曲率のしきい值の 決定には，より多くのデータについて試みる必要があ る。また，今回は表面積を最小とする経路を最適経路 として比較評価したが，この評価基準は絶対的なもの ではない。今後, 体積最大経路など他の評価基準につ いても検討する必要がある。

最後に, 本研究で使用した CT データ, MRI のデー タを提供していたたいた近畿大学医学部の田中清介教 授，PL 病院の松倉登整形外科部長に感謝します。 （日本図学会 1990 年度全国大会にて口頭発表ずみ）

\section{参考文献}

1 ）上木登, 桶口清文, 高橋義造. “頭部 CT 画像汃 らの脳形状の高精度構成とその篮淡 3 次元表示”, 電子通信学会論文誌, Vol. J69-D, No.10， (1986), 1518-1527.

2 ) Bui Tuong Phong, "Illumination for Computer Genarated Pictures", CACM, 18, 6(1975), 311-317.

3 ) H. Fuchs, Z. M. Kedem, and S. P. Uselton, “Optimal Surface Reconstruction from Planar Contours", CACM, 20, 10(1977), 693-702.
4 ) H. N. Christiansen \& T. W. Sederberg., "Conversion of Complex Contour Line Definitions into Polygonal Element Mosaics", Computer Graphics, 13, 2(1987), 187-192.

5 ) S. Ganapathy, T. G. Dennehy. "A New General Triangulation Method for Planar Contours", Computer Graphics, 16, 3(1982), 69-75.

An Improved General Triangulation Method for Planar Contours

Takao MIYAMOTO

Seiji KOYAMA

Hideo KOSAKO

Reiji TSURUNO

Sadahiko NAGAE

Approximating the surface spanning a given set of 3D points as a polyhedron of triangular faces (triangulation) is one of the significant problems, and has many applications in the fields of computer graphics and computer vision. In this paper, several solutions to this problem are reviewed. These solutions have the problem that contour lines of irregular surfaces, such as found in nature, do not lend themselves to curve fitting. We developed an efficient and precise heuristic method for triangulation of the 3D surface formed by spanning a set of planar contours. The most efficient triangulation is presented newly in the paper by judging from the similarity in the shapes of adjacent contours.And this method can generate without depending on the shapes of contour lines. The program was designed to interface contour definitions of the components of a human head. 